\title{
Urinary Excretion of Interleukin-6 in Pediatric IgA Nephropathy Patients
}

Katsuyoshi Kanemoto $^{1 *}$, Ryutaro Matsumura², Michiko Anzai ${ }^{1}$, Chieko Matsumura ${ }^{1}$ and Hideaki Kurayama ${ }^{1}$

${ }^{1}$ Department of Pediatrics, National Hospital Organization Chiba-East Hospital, Chiba, Japan

${ }^{2}$ Department of Rheumatology, Allergy and Clinical Immunology of the Clinical Research Center, National Hospital Organization Chiba-East Hospital, Chiba, Japan

\begin{abstract}
Objective: Urinary excretion of interleukin-6 (U-IL6) has been reported to be elevated and to represent the disease activity in adult IgA nephropathy (IgAN). We investigated the significance and the utility of U-IL6 activity in pediatric IgAN patients.
\end{abstract}

Methods: We evaluated 55 pediatric IgAN patients (4-18 years; mean age, 10.7 years) and 53 healthy controls from 2007 to 2012 . The U-IL6 concentrations (pg/mg creatinine) were estimated by ELISA at the time of renal biopsy and after 6 months of prednisolone therapy for IgAN. In addition, we evaluated the correlations between the U-IL6 level and clinic pathological parameters of IgAN. To elucidate the usefulness for early diagnosis of IgAN, we investigated U-IL6 in 45 asymptomatic hematuria (ASH) children who were diagnosed by school urine screening program.

Results: U-IL6 activity was significantly higher in IgAN patients than in healthy controls and ASH children $(\mathrm{p}<0.01)$. In addition, U-IL6 was significantly decreased after 6 months of prednisolone therapy $(p<0.01)$. With regard to the clinicopathological parameters, U-IL6 activity was correlated with degree of proteinuria $(p<0.01, r=0.72)$, hematuria $(p<0.01, r=0.54)$, urinary podocyte score $(p<0.01, r=0.59)$, mesangial cell proliferation $(p<0.05)$, endocapillary proliferation $(p<0.01)$, and crescent formation $(p<0.05)$. Interestingly, five children who transited to IgAN from ASH during the observation period showed high U-IL6 levels $(p<0.01)$.

Conclusions: The present results also suggest that U-IL6 represents the disease activity in pediatric IgAN patients. We consider that it is important to evaluate U-IL6 in patients with ASH detected by school urinary screening program for early detection and prevention of unrecognized progression of IgAN.

Keywords: Asymptomatic hematuria; IgA nephropathy; Interleukin-6; Prednisolone; School urinary screening program; Urine biomarker; Urinary podocyte

\section{Short Summary}

Similar to previous reports, urinary excretion of IL-6 (U-IL6) was found to represent the disease activity in pediatric IgAN patients. It may be useful to evaluate U-IL6 activity in patients with asymptomatic hematuria detected by school urinary screening program for early detection and prevention of unrecognized progression of IgAN.

\section{Introduction}

IgA nephropathy (IgAN) is currently the most common form of primary glomerulonephritis around the world [1,2]. Long-term follow-up studies have shown that the disease progresses to renal failure in $20-50 \%$ of adult patients over 20 years [3]. Although the prognosis of childhood IgAN is believed to be benign, a study of 241 Japanese pediatric IgAN patients showed that $11 \%$ of them exhibited end-stage renal failure within 15 years [4]. The glomerular lesions are characterized by immune deposits of mainly IgA1 in the mesangium and by mesangial cell proliferation and extracellular matrix expansion [5]. Recent reports have suggested that several cytokines and growth factors, which are produced locally in the kidney, are directly related to the extent of the histological changes [6,7].

Interleukin (IL)-6 is produced in vivo by monocytes/macrophages, neutrophils, and endothelial, mesangial, and epithelial cells $[8,9]$. IL- 6 has been identified within the glomeruli of IgAN patients and contributes to the proliferation of mesangial cells [10]. Increased urinary excretion of IL-6 (U-IL6) has been reported in adult IgAN patients with a progressive clinical course [11-13]. To date, high U-IL6 has not been reported in pediatric IgAN patients.

In 1973, the Japanese Ministry of Education began a mass urine screening program for school children aimed at the early detection of insidious renal disease $[14,15]$. Children with both hematuria and proteinuria have been suspected to have serious glomerular diseases (mainly IgAN) and are indicated for a renal biopsy [15]. On the other hand, children with isolated asymptomatic hematuria (ASH) have been generally considered to have a good prognosis and are only indicated for a renal biopsy when they show proteinuria associated with hematuria [16]. Measurement of U-IL6 may be one of the useful markers for early detection of pediatric IgAN patients who initially show only ASH in the school urinary screening program.

In the present study, we measured the U-IL6 activity in pediatric IgAN patients and ASH children to demonstrate its potential association with the disease severity and its value as a urinary marker for early detection of IgAN.

\section{Subjects and Methods}

\section{Patients}

The investigation complied with the principles outlined in the Declaration of Helsinki. Our IRB/Ethics Committee decided that approval was not required for this study. In the study, we investigated 55 pediatric IgAN patients ( 31 males and 24 females; mean age: 10.5 \pm 3.2 years) newly diagnosed with IgAN, 45 children with ASH (22

*Corresponding author: Katsuyoshi Kanemoto, Department of Pediatrics, National Hospital Organization Chiba-East Hospital, 763 Nitona, Chuo-ku, Chiba 260-8712, Japan, Tel: +81-43-261-5171; Fax: +81-43-268-2613; E-mail: k.katsuy@cehpnet.com

Received January 17, 2014; Accepted February 18, 2014; Published February 25, 2014

Citation: Kanemoto K, Matsumura R, Anzai M, Matsumura C, Kurayama H (2014) Urinary Excretion of Interleukin-6 in Pediatric IgA Nephropathy Patients. J Nephrol Therapeutic S11: 004. doi:10.4172/2161-0959.S11-004

Copyright: (c) 2014 Kanemoto K, et al. This is an open-access article distributed under the terms of the Creative Commons Attribution License, which permits unrestricted use, distribution, and reproduction in any medium, provided the original author and source are credited. 
males and 23 females; mean age: $10.0 \pm 3.9$ years) detected by the urinary screening program, and 53 healthy controls (30 males and 23 females; mean age: $9.3 \pm 4.4$ years) between April 2007 and June 2012 in our hospital. A renal biopsy was performed in all IgAN patients at the beginning of the study before any treatment was applied. After diagnosis, the ASH children were followed up regularly (every 2 months) for their hematuria on an outpatient basis for a mean period of $1.5 \pm 2.1$ years. Fifty-one IgAN patients were treated with prednisolone ( $1 \mathrm{mg} / \mathrm{kg}$ body weight/day, maximum $40 \mathrm{mg} /$ day initially for 4 weeks, followed by gradual tapering to $5 \mathrm{mg}$ every other day over a 12-month period), warfarin, and dipyridamole. The mean duration of treatment was $24 \pm 8$ months and the mean follow-up period was $2.7 \pm 1.5$ years.

\section{Diagnostic definitions}

Hypertension was defined as blood pressure above the 95th percentile for the sex, age, and height percentile. Renal insufficiency was defined as an estimated glomerular filtration rate (eGFR) of $<90$ $\mathrm{mL} / \mathrm{min} / 1.73 \mathrm{~m}^{2}$ at the renal biopsy, which was calculated using the Schwartz formula. Proteinuria was evaluated using the early morning urinary total protein/creatinine $(\mathrm{Cr})$ ratio $(\mathrm{g} / \mathrm{g} \mathrm{Cr})$. The diagnosis of nephrotic syndrome was based on heavy proteinuria (urinary total protein/Cr ratio of $>3.0 \mathrm{~g} / \mathrm{g} \mathrm{Cr}$ ) in conjunction with hypoalbuminemia $(<2.5 \mathrm{~g} / \mathrm{dL})$ and hypercholesterolemia $(>220 \mathrm{mg} / \mathrm{dL})$. Hematuria was quantified using dipsticks, and macrohematuria was quantified as scores of $4+$. Microhematuria was defined as the presence of more than five red blood cells per high-power field (hpf) on optical microscopy of the urine. Heavy, moderate, and mild microhematuria were defined as $\geq 50 / \mathrm{hpf}, \geq 20$ to $<50 / \mathrm{hpf}$, and $<20 / \mathrm{hpf}$, respectively. Urinary podocytes (U-pods) were quantified using samples obtained immediately after the first urination in the morning. U-pods were stained by an immunofluorescence technique as reported previously $[17,18]$. Urine sediments were incubated with an anti-human podocalyxin monoclonal antibody as reported previously [19]. The investigators who scored the U-pod numbers were medical technicians at an outside diagnostic center in Tokyo. The U-pod number was defined positive for values of $>1.0 / \mathrm{mL}$.

\section{Urinary excretion of interleukin-6}

The first morning urine samples collected on the day of the renal biopsy and after 6 months of prednisolone therapy were evaluated and compared with those from the healthy controls. In ASH children, the first morning urine samples were collected within 3 months of their diagnosis by the urinary screening program. The U-IL6 levels were measured using a commercially available kit involving a chemiluminescent enzyme immunoassay (Human IL-6 CLEIA; Fujirebio, Tokyo, Japan). The detection limit of the assay was $0.2 \mathrm{pg} /$ $\mathrm{mL}$. The U-IL6 level was normalized for the urinary creatinine (Ucr) concentration and expressed as $\mathrm{pg} / \mathrm{mg}$ Ucr.

\section{Histological study}

The diagnosis was made by an adequate renal biopsy using light microscopy and immunofluorescence. Renal tissues were taken with a $16 \mathrm{G}$ biopsy needle gun, fixed in $10 \%$ neutral formalin, embedded in paraffin, and examined by light microscopy in multiple sections $(4 \mu \mathrm{g}$ each). The histological study included hematoxylin and eosin (HE), periodic acid-Schiff (PAS), Masson trichrome and reticulin silver methenamine staining. Mesangial cell proliferation was scored as 0 (1-3 mesangial cells/mesangial area), 1 (4-5 mesangial cells/mesangial area), 2 (6-7 mesangial cells/mesangial area), and 3 ( $>8$ mesangial cells/ mesangial area). The degree of mesangial proliferation was expressed as focal $(<50 \%$ mesangial proliferative glomeruli/total glomeruli) and diffuse ( $\geq 50 \%$ mesangial proliferative glomeruli/total glomeruli). These pathological variables including endocapillary hypercellularity and cellular or fibrocellular crescents were assessed according to the Oxford classification [20]. Briefly, endocapillary proliferation and crescent formation were classified by their presence or absence on PASor Masson trichrome-stained sections.

\section{Statistical analysis}

Statistical analyses were performed using SPSS ver. 20 for Windows (SPSS, IBM, Tokyo, Japan). Demographic data other than age are reported as percentages. Age (mean $\pm \mathrm{SD}$ ) and median age revealed a bimodal distribution. The Mann-Whitney U-test and ANOVA were used to assess the U-IL6 differences between the groups, respectively. Pearson and Spearman coefficients were used for evaluation of the correlations between parametric and non-parametric variables, respectively. Values of $\mathrm{p}<0.05$ were considered to indicate statistical significance.

\section{Results}

\section{Clinical data}

From April 2007 to June 2012, a total of 55 Japanese children with IgAN (31 males and 24 females; average age: $10.5 \pm 3.2$ years) were admitted and underwent a renal biopsy. Among them, 51 patients received prednisolone therapy and two patients received angiotensinconverting enzyme inhibitors and dipyridamole. Table 1 show the clinical and laboratory findings of the IgAN patients at the renal biopsy and after 6 months of prednisolone therapy. Five patients (9.1\%) exhibited nephrotic syndrome and one patient had renal insufficiency at the time of renal biopsy. Macrohematuria was observed in 17 patients (30.9\%). The mean proteinuria was $1.41 \pm 1.21 \mathrm{~g} / \mathrm{g} \mathrm{Cr}$ and the mean $\mathrm{U}$-pod number was $3.76 \pm 1.82 / \mathrm{mL}$. After 6 months of prednisolone therapy, there were significant $(\mathrm{p}<0.05)$ reductions in the proteinuria $(1.41 \pm 1.21$ to $0.22 \pm 0.44 \mathrm{~g} / \mathrm{g} \mathrm{Cr})$ and $\mathrm{U}$-pod number $(3.76 \pm 1.82$ to $0.85 \pm 0.91 / \mathrm{mL})$. Nephrotic syndrome, renal insufficiency, and macrohematuria were not found in the 51 IgAN patients after 6 months of prednisolone therapy. In addition, the degrees of microscopic hematuria had improved (severe: $69.1 \%$ to $3.9 \%$; moderate: $20 \%$ to $17.6 \%$; mild: $12 \%$ to $78.4 \%)$.

\begin{tabular}{|l|c|c|}
\hline & At Biopsy & $\mathbf{6}$ months after PSL \\
\hline $\mathrm{n}$ & 55 & 51 \\
\hline $\mathrm{SBP}(\mathrm{mmHg})$ & $116 \pm 21$ & $114 \pm 19$ \\
\hline $\mathrm{DBP}(\mathrm{mmHg})$ & $68 \pm 19$ & $63 \pm 18$ \\
\hline eGFR $\left(\mathrm{ml} / \mathrm{min} / 1.73 \mathrm{~m}^{2}\right)$ & $124 \pm 42.1$ & $129 \pm 36.3$ \\
\hline Proteinuria(g/g Cr) & $1.41 \pm 1.21$ & $0.22 \pm 0.44$ * \\
\hline Macrohematuria & $17 / 55(30.9 \%)$ & $0 / 51(0 \%)$ \\
\hline Microhematuria $\mathrm{RBC} \geq 50 / \mathrm{hpf}$ & $21 / 55(38.2 \%)$ & $2 / 51(3.9 \%)$ \\
\hline $20 \leq \mathrm{RBC}<50 / \mathrm{hpf}$ & $11 / 55(20 \%)$ & $9 / 51(17.6 \%)$ \\
\hline RBC $<20 / \mathrm{hpf}$ & $6 / 55(12 \%)$ & $40 / 51(78.4 \%)$ \\
\hline Urinary podocyte(/ml) & $3.76 \pm 1.82$ & $0.85 \pm 0.91$ * \\
\hline Nephrotic syndrome & $5 / 55(9.1 \%)$ & $0 / 51(0 \%)$ \\
\hline Renal insufficiency & $1 / 55(2 \%)$ & $0 / 51(0 \%)$ \\
\hline
\end{tabular}

PSL: prednisolone; SBP: systolic blood pressure; DBP: diastolic blood pressure; hpf: high-power field; eGFR: estimated glomerular filtration rate; RBC: red blood cells.

${ }^{*} \mathrm{p}<0.05$

Table 1: Clinical characteristics and laboratory findings of the IgA nephropathy patients at the renal biopsy and after 6 months of prednisolone therapy. 
Citation: Kanemoto K, Matsumura R, Anzai M, Matsumura C, Kurayama H (2014) Urinary Excretion of Interleukin-6 in Pediatric IgA Nephropathy Patients. J Nephrol Therapeutic S11: 004. doi:10.4172/2161-0959.S11-004

Page 3 of 5

\section{Urinary excretion of interleukin-6 in $\operatorname{Ig} A$ nephropathy children}

The IgAN patients at the time of the renal biopsy had significantly higher U-IL6 levels than the healthy controls $(9.1 \pm 9.13$ vs. $1.5 \pm 0.33$ $\mathrm{pg} / \mathrm{mg}$ Ucr, $\mathrm{p}<0.01$, Figure 1). After 6 months of prednisolone therapy, the U-IL6 level was significantly reduced in the 51 IgAN patients $(9.1 \pm$ 9.13 to $1.78 \pm 1.76 \mathrm{pg} / \mathrm{mg}$ Ucr, $\mathrm{p}<0.01$, Figure 2).

\section{Correlations of urinary excretion of interleukin- 6 with clinical and histological findings}

Table 2 shows the correlations of the U-IL6 level with the clinical and histological findings. In the clinical findings, the U-IL6 level of the IgAN patients at the renal biopsy showed positive correlations with the degree of proteinuria $(r=0.72, p<0.01)$, hematuria $(r=0.54$, $\mathrm{p}<0.01)$, and $\mathrm{U}$-Pod number $(\mathrm{r}=0.59, \mathrm{p}<0.01)$. In contrast, the U-IL6 level had a negative correlation with the eGFR $(\mathrm{r}=-0.34, \mathrm{p}=0.015)$. In the histological findings, the U-IL6 level of the IgAN patients at the renal biopsy showed positive correlations with the degree of mesangial hypercellularity (proliferation score $2-3$ vs. $0-1, p=0.047$ ), crescent formation (cellular or fibrocellular crescent positive vs. negative, $\mathrm{p}=0.042$ ), and endocapillary proliferation (positive vs. negative,

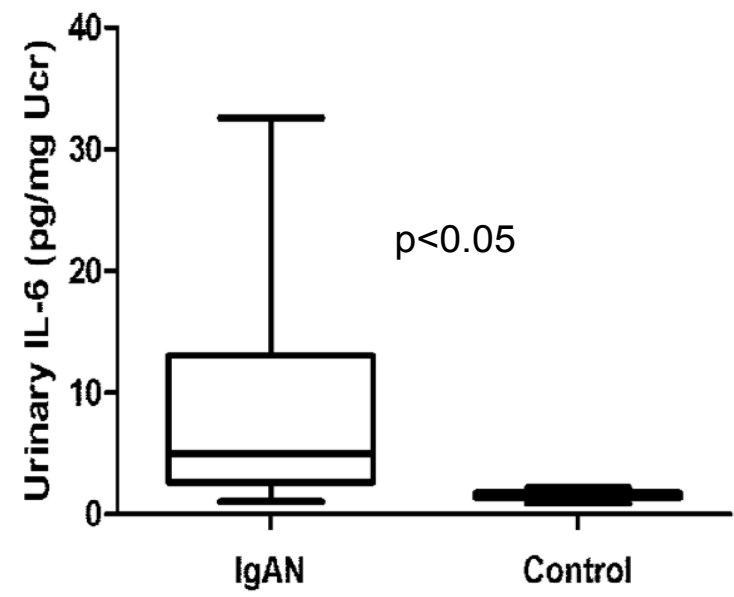

Figure 1: Urinary IL-6 levels at the renal biopsy in the pediatric IgA nephropathy patients (IgAN) and healthy controls.

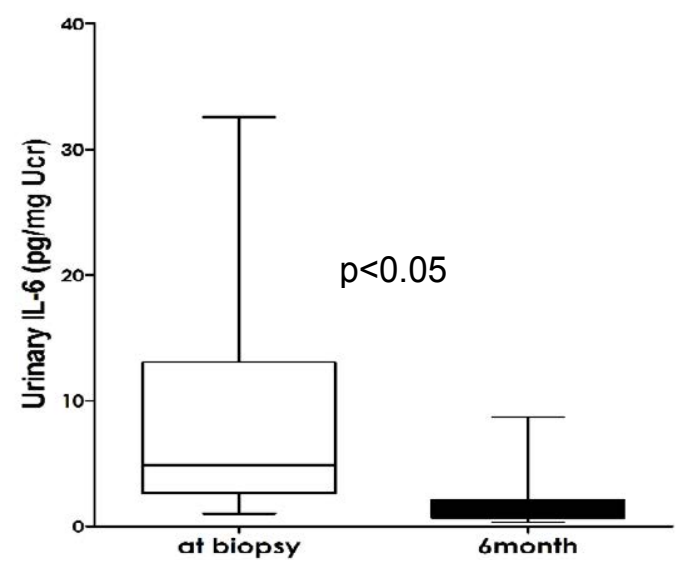

Figure 2: Urinary IL-6 levels at the renal biopsy and after 6 months of prednisolone therapy in the pediatric IgA nephropathy (IgAN) patients.

\begin{tabular}{|c|c|c|}
\hline \multicolumn{3}{|c|}{ Urinary IL-6 } \\
\hline & $\mathbf{r}$ & $\mathbf{p}$ \\
\hline Proteinuria(g/g Cr) & 0.72 & $<0.01$ \\
\hline Hematuria (score) & 0.54 & $<0.01$ \\
\hline Urinary podocyte(/ml) & 0.59 & $<0.01$ \\
\hline eGFR(ml/min/1.73 m²) & -0.34 & 0.015 \\
\hline \multicolumn{3}{|c|}{ Mesangial cell proliferation } \\
\hline $2-3(n=23)$ vs. & - & 0.047 \\
\hline $0-1(n=32)$ & - & \\
\hline \multicolumn{3}{|c|}{ Mesangial proliferative glomeruli } \\
\hline diffuse $(n=24)$ vs. & - & NS \\
\hline focal $(n=31)$ & - & \\
\hline \multicolumn{3}{|c|}{ Cellular/fibrocellular crescent } \\
\hline positive(n=24) vs. & - & 0.042 \\
\hline negative $(n=31)$ & - & \\
\hline \multicolumn{3}{|c|}{ Endocapillary proliferation } \\
\hline positive(n=29) vs. & - & $<0.01$ \\
\hline negative $(n=26)$ & - & \\
\hline
\end{tabular}

eGFR, estimated glomerular filtration rate; NS, not significant

Hematuria scores (red blood cells/high-power field): $0,<10 ; 1, \geq 10$ to $<20 ; 2, \geq 20$ to $<30 ; 3, \geq 30$ to $<50 ; 4, \geq 50$ to $<100 ; 5, \geq 100$

Table 2: Correlations of urinary excretion of interleukin-6 with clinical and histological. Findings.

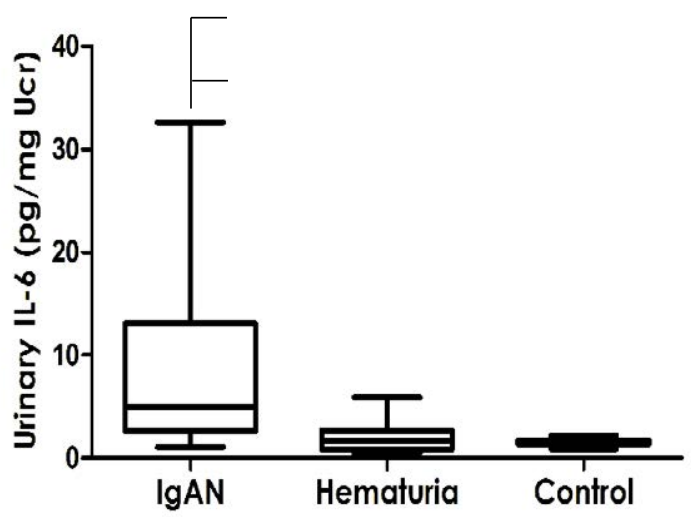

Figure 3: Urinary IL-6 levels at the renal biopsy in the pediatric IgA nephropathy (IgAN) patients, asymptomatic hematuria children, and controls. NS: not significant.

$\mathrm{p}<0.01)$. The percentages of mesangial proliferative glomeruli did not differ significantly (diffuse vs. focal, $\mathrm{p}>0.05$ ).

Urinary excretion of interleukin-6 in asymptomatic hematuria children

Figure 3 shows the U-IL6 levels at the renal biopsy of the $\operatorname{IgA}$ patients and ASH children. The U-IL6 levels were significantly lower in the $45 \mathrm{ASH}$ children diagnosed by the urine screening program than in the IgAN patients $(1.96 \pm 1.3$ vs. $9.1 \pm 9.13 \mathrm{pg} / \mathrm{mg}$ Ucr, $\mathrm{p}<0.01$ by ANOVA). On the other hand, the U-IL6 levels in the ASH children did not differ significantly from those in the healthy controls (1.96 \pm 1.3 vs. $1.5 \pm 0.33 \mathrm{pg} / \mathrm{mg}$ Ucr, $\mathrm{p}>0.05$ by ANOVA). Among the $45 \mathrm{ASH}$ children, three males and two females transited to IgAN during the observation period. Table 3 shows the clinical and laboratory findings of these five children who transited from ASH to IgAN. At the school urine screening tests, all five children showed only microhematuria and did not have positive proteinuria. In addition, their U-pod numbers remained within the normal limit $(<1.0 / \mathrm{mL})$. However, the U-IL6 levels 
Page 4 of 5

\begin{tabular}{|c|c|c|c|c|c|c|c|c|c|c|}
\hline \multirow[b]{2}{*}{ No. } & \multirow[b]{2}{*}{ Sex } & \multirow[b]{2}{*}{ Age } & \multicolumn{4}{|c|}{ At school urine test } & \multicolumn{4}{|c|}{ At IgAN onset } \\
\hline & & & $\mathrm{Up}(\mathrm{g} / \mathrm{g} \mathrm{Cr})$ & $\mathrm{RBC}(/ \mathrm{hpf})$ & U-IL6/Cr & U-pod (/ml) & duration of IgAN onset (month) & style of IgAN onset & U-IL6/Cr & U-pod $(/ \mathrm{ml})$ \\
\hline 1 & $M$ & 7 & 0.15 & $30-49$ & 3.7 & 0.5 & 12 & Macro Ht & 7.14 & 9.6 \\
\hline 2 & M & 10 & 0.13 & $100 \uparrow$ & 3.13 & 0.7 & 3 & appear Up & 3.84 & 2.5 \\
\hline 3 & $M$ & 10 & 0.06 & $20-29$ & 5.87 & 0.6 & 5 & appear Up & 7.43 & 1.9 \\
\hline 4 & $\mathrm{~F}$ & 12 & 0.17 & $50-99$ & 4.18 & 0.8 & 11 & appear Up & 5.39 & 4.6 \\
\hline 5 & $\mathrm{~F}$ & 14 & 0.10 & $30-49$ & 4.38 & 0.5 & 8 & Macro Ht & 8.22 & 5.5 \\
\hline \multirow{2}{*}{\multicolumn{3}{|c|}{ Mean }} & 0.13 & - & $4.3 *$ & 0.62 & 7.7 & - & 6.26 & 4.81 \\
\hline & & & & & \pm 1.18 & & & & \pm 1.67 & \pm 3.5 \\
\hline other $41 \mathrm{Ht}$ & & 10.2 & 0.08 & - & 1.61 & 0.37 & 18.3 & - & - & - \\
\hline children & & $3-$ & & & \pm 1.17 & & & & & \\
\hline range & & 18 & $0.02-0.17$ & - & $0.4-5.87$ & $0-0.8$ & $3-81$ & - & - & - \\
\hline
\end{tabular}

IgAN, IgA nephropathy; Up, urinary protein; RBC, red blood cells; U-IL6, urinary excretion of interleukin-6; U-pod, urinary podocytes; Ht, hematuria. ${ }^{*} \mathrm{p}<0.05$

Table 3: Clinical and laboratory findings of four children who transited from asymptomatic hematuria to IgA nephropathy during the observation period.

in these five children were significantly higher than those in the other 41 ASH children $(4.3 \pm 1.18$ vs. $1.61 \pm 1.17 \mathrm{pg} / \mathrm{mg}$ Ucr, $\mathrm{p}<0.05)$. At IgAN onset, all five children showed positive proteinuria and increased U-pod numbers $(4.81 \pm 3.5 / \mathrm{mL})$. Their U-IL6 levels tended to increase steadily with the onset of IgAN $(4.3 \pm 1.18$ to $6.26 \pm 1.67 \mathrm{pg} / \mathrm{mg}$ Ucr, respectively)

\section{Discussion}

Examination of urine has gained more interest during the last few years. Urinary cytokine excretion may reflect the severity of histological damage and predict the response to treatment. Several cytokines and growth factors have been investigated in the urine of IgAN patients to assess their value as predictive markers of disease severity. Among them, transforming growth factor- $\beta$, monocyte chemo attractant protein-1, and IL- 6 have been reported to be upregulated in accordance with the disease severity in IgAN patients [12,21-25]. IL-6 is a multifocal cytokine that stimulates the proliferation of fibroblasts and mesangial cells [26]. The involvement of IL-6 in the pathogenesis of IgAN has been reported by various studies. Anionic polymeric IgA1 from IgAN patients incubated with human mesangial cells resulted in increased cell proliferation and synthesis of tumor necrosis factor- $\alpha$ and IL-6 [27]. IL-6 gene transcription was identified within the glomeruli of IgAN patients and contributed to the proliferation of mesangial cells $[10,28]$.

In the present study, we first demonstrated that U-IL6 increased in parallel with the severity of both the clinical and histological findings in pediatric IgAN patients. In addition, similar to a previous study [22], our study showed that the U-IL6 levels in pediatric IgAN patients were increased at the time of the renal biopsy and were significantly reduced after prednisolone therapy. Although the U-IL6 level was not correlated with the degree of mesangial proliferative glomeruli (diffuse or focal), we found that U-IL6 was correlated with the acute inflammatory glomerular changes, such as mesangial hypercellularity, cellular/ fibrocellular crescent formation, and endocapillary proliferation. Our findings indicate that combined measurements of U-IL6 and U-pods may provide useful information about the severity of glomerular inflammation in pediatric IgAN before a renal biopsy.

In 1973, the Japanese Ministry of Education began a mass urine screening program for school children aged 6-18 years aimed at early detection of insidious renal diseases [14,15]. Children with both hematuria and proteinuria have been suspected to have serious glomerular diseases and are indicated for a renal biopsy [15]. Therefore, diagnosis and treatment of IgAN are generally started early in the disease course in Japan. On the other hand, the prognosis of children with ASH is considered to be good, and a renal biopsy is only indicated for children with ASH who also show proteinuria [16]. Hisano et al. [16] reported that seven of $136 \mathrm{ASH}$ children were diagnosed with IgAN by a renal biopsy because of evidence for proteinuria or macrohematuria throughout the follow-up period. Among these seven IgAN children, one child exhibited renal insufficiency at the renal biopsy and developed persistent proteinuria. Hence, we think that a more benign prognosis of IgAN may be approved by the identification and validation of urinary markers that can distinguish the presence of IgAN from ASH in children.

The scoring of U-pods has been reported to be one of the useful clinical diagnostic tools for the acute state of IgAN and HenochSchönlein purpura nephritis [18]. The present study also showed that higher U-pod numbers were found in pediatric IgAN patients. In contrast, all the ASH children, including the five patients who transited to IgAN during the observation period, showed normal U-pod numbers. Therefore, we consider that scoring of $U$-pods is not a suitable marker for early distinction of IgAN from ASH. In the present study, the five IgAN children who progressed from ASH showed higher U-IL6 activity without proteinuria or macrohematuria. Although the present study had a small sample size and was a single-center analysis, we consider that evaluation of U-IL6 in children with ASH may be one of the useful markers for early detection and prevention of unrecognized progression of IgAN.

In summary, the present results suggest that higher U-IL6 reflects the disease severity in pediatric IgAN patients. In addition, the significant reduction in U-IL6 after prednisolone therapy may represent a suitable marker of the disease activity. We propose that it is important to evaluate U-IL6 in patients with ASH detected by the school urinary screening program for early detection and prevention of unrecognized progression of IgAN. However, further studies are required to elucidate whether U-IL6 measurements can be used as a noninvasive tool to select children who may need more intensive examinations including a renal biopsy.

\section{Acknowledgement}

Financial support: This study was not supported by any research grants or funds. Conflict of interest: None declared.

\section{References}

1. Donadio JV, Grande JP (2002) IgA nephropathy. N Engl J Med 347: 738-748.

2. Barratt J, Feehally J (2005) IgA nephropathy. J Am Soc Nephrol 16: 2088-2097. 
Citation: Kanemoto K, Matsumura R, Anzai M, Matsumura C, Kurayama H (2014) Urinary Excretion of Interleukin-6 in Pediatric IgA Nephropathy Patients. J Nephrol Therapeutic S11: 004. doi:10.4172/2161-0959.S11-004

Page 5 of 5

3. Appel GB, Waldman M (2006) The IgA nephropathy treatment dilemma. Kidney Int 69: 1939-1944.

4. Yoshikawa N, Tanaka R, lijima K (2001) Pathophysiology and treatment of IgA nephropathy in children. Pediatr Nephrol 16: 446-457.

5. van der Boog PJ, van Kooten C, de Fijter JW, Daha MR (2005) Role of macromolecular IgA in IgA nephropathy. Kidney Int 67: 813-821.

6. Rovin BH, Song H, Birmingham DJ, Hebert LA, Yu CY, et al. (2005) Urine chemokines as biomarkers of human systemic lupus erythematosus activity. $J$ Am Soc Nephrol 16: 467-473

7. Julian BA, Wittke S, Haubitz M, Zürbig P, Schiffer E, et al. (2007) Urinary biomarkers of IgA nephropathy and other IgA-associated renal diseases. World J Urol 25: 467-476.

8. Hirano T, Akira S, Taga T, Kishimoto T (1990) Biological and clinical aspects of interleukin 6. Immunol Today 11: 443-449.

9. Pedreanez A, Viera N, Rincon J, Mosquera J (2006) Increased IL-6 in supernatant of rat mesangial cell cultures treated with erythrogenic toxin type $B$ and its precursor isolated from nephritogenic streptococci. Am J Nephrol 26: 75-81.

10. Lim CS, Yoon HJ, Kim YS, Ahn C, Han JS, et al. (2003) Clinicopathological correlation of intrarenal cytokines and chemokines in $\lg A$ nephropathy. Nephrology (Carlton) 8: 21-27.

11. Taniguchi Y, Yorioka N, Kumagai J, Katsutani M, Kuratsune M, et al. (1999) Interleukin-6 localization and the prognosis of IgA nephropathy. Nephron 81 94-98.

12. Harada K, Akai Y, Kurumatani N, Iwano M, Saito $Y$ (2002) Prognostic value of urinary interleukin 6 in patients with IgA nephropathy: an 8-year follow-up study. Nephron 92: 824-826.

13. Stangou M, Alexopoulos E, Papagianni A, Pantzaki A, Bantis C, et al (2009) Urinary levels of epidermal growth factor, interleukin-6 and monocyte chemoattractant protein-1 may act as predictor markers of renal function outcome in immunoglobulin A nephropathy. Nephrology (Carlton) 14: 613-620.

14. Kitagawa T (1988) Lessons learned from the Japanese nephritis screening study. Pediatr Nephrol 2: 256-263.

15. Hisano S, Ueda K (1989) Asymptomatic haematuria and proteinuria: rena pathology and clinical outcome in 54 children. Pediatr Nephrol 3: 229-234.

16. Hisano S, Kwano M, Hatae K, Kaku Y, Yamane I, et al. (1991) Asymptomatic isolated microhaematuria: natural history of 136 children. Pediatr Nephrol 5 : 578-581.
17. Hara M, Yanagihara T, Kihara I (2001) Urinary podocytes in primary focal segmental glomerulosclerosis. Nephron 89: 342-347.

18. Hara M, Yamamoto T, Yanagihara T, Takada T, Itoh M, et al. (1995) Urinary excretion of podocalyxin indicates glomerular epithelial cell injuries in glomerulonephritis. Nephron 69: 397-403.

19. Hara M, Yanagihara T, Takada T, Itoh M, Matsuno M, et al. (1998) Urinary excretion of podocytes reflects disease activity in children with glomerulonephritis. Am J Nephrol 18: 35-41.

20. Working Group of International IgA Nephropathy Network and the Renal Pathology Society, Cattran DC, Coppo R, Cook HT, et al. (2009) The Oxford classification of IgA nephropathy: rationale, clinic pathological correlations, and classification. Kidney Int 76: 534-545

21. Wagrowska-Danilewicz M, Danilewicz M, Stasikowska O (2005) CC chemokines and chemokine receptors in $\lg$ A nephropathy (IgAN) and in non-lgA mesangia proliferative glomerulonephritis (MesProGN). the immunohistochemical comparative study. Pol J Pathol 56: 121-126.

22. Kalliakmani P, Nakopoulou L, Tsakas S, Gerolymos M, Papasotiriou M, et al. (2011) Urinary interleukin-6 (IL-6) and transforming growth factor (TGF-Î2) levels in corticosteroidtreated patients with IgA nephropathy. Clin Nephrol 76 144-150.

23. Hrvacevia R, Topalov D, Stojanovic R, Lilic D, Dimitrijevic J, et al. (1996) [Serum and urinary interleukin-6 levels in patients with primary glomerulonephritis]. Srp Arh Celok Lek 124 Suppl 1: 40-42.

24. Haramaki R, Tamaki K, Fujisawa M, Ikedo H, Haramaki N, et al. (2001) Steroid therapy and urinary transforming growth factor-beta1 in IgA nephropathy. Am J Kidney Dis 38: 1191-1198.

25. Park HC, Xu ZG, Choi S, Goo YS, Kang SW, et al. (2003) Effect of losartan and amlodipine on proteinuria and transforming growth factor-beta1 in patients with IgA nephropathy. Nephrol Dial Transplant 18: 1115-1121.

26. Liang B, Gardner DB, Griswold DE, Bugelski PJ, Song XY (2006) Antiinterleukin-6 monoclonal antibody inhibits autoimmune responses in a murine model of systemic lupus erythematosus. Immunology 119: 296-305.

27. Leung JC, Tang SC, Chan LY, Chan WL, Lai KN (2008) Synthesis of TNF-alpha by mesangial cells cultured with polymeric anionic IgA--role of MAPK and NFkappaB. Nephrol Dial Transplant 23: 72-81.

28. Ballardie FW, Gordon MT, Sharpe PT, Darvill AM, Cheng H (1994) Intrarena cytokine mRNA expression and location in normal and IgA nephropathy tissue: TGF alpha, TGF beta, IGF 1, IL-4 and IL-6. Nephrol Dial Transplant 9: 1545-1552.
This article was originally published in a special issue, Pediatric Nephrology handled by Editor(s). Moazzam Hossain, Bangabandhu Sheikh Mujib Medical University, Bangladesh 